\title{
TEACHING TARGET VALUE DESIGN: A SIMULATION
}

\author{
Ganesh Devkar ${ }^{1}$, Jyoti Trivedi ${ }^{2}$, and Devanshu Pandit ${ }^{3}$
}

\begin{abstract}
Target Value Design (TVD) is a promising lean tool that drives the design process of a construction project with the sole intent of value maximization for the client within targeted cost. The mainstreaming of this tool in design and construction practice requires not only imparting knowledge about this tool but also providing hand on experience to the budding design and construction management students. The aim of this paper is to describe the development and testing of TVD simulation exercise. The research methodology adopted is a combination of qualitative approach - a case study of simulation exercise, and quantitative approach - questionnaire survey amongst simulation participants. The simulation involves a role play exercise for students to understand the collaboration between designers, owner, and contractor in the design process. Along with these three main stakeholders, the simulation involved BIM modeler for providing rapid cost feedback during the preparation of design alternatives. The simulation was tested on students of the master's programme in Construction Engineering and Management in an Indian university. The research highlights the effectiveness of the simulation in helping students understand the benefits of TVD. Further, the participants of this simulation exercise expressed the value addition of BIM in generating rapid cost feedback during design iterations. Despite the limited scope selected for the simulation and the challenges offered by classroom environments, this simulation improved the practical understanding of IPD and TVD amongst the students.
\end{abstract}

\section{KEYWORDS}

Lean construction, target value design (TVD), collaboration, action learning

\section{INTRODUCTION}

There exists various lean tools and techniques for improving the design of construction projects. Target Value Design (TVD) is one of the prominent techniques which not only addresses the procedural dimension, but also the cultural dimension of the design process.

1 Associate Professor, Faculty of Technology, CEPT University, Ahmedabad - 380009, India, +919099010303, ganesh.devkar@cept.ac.in

2 Assistant Professor, Faculty of Technology, CEPT University, Ahmedabad - 380009, India, +919925009609, jyoti@cept.ac.in

3 Professor, Faculty of Technology, CEPT University, Ahmedabad - 380009, India, +919909956661, devanshu@cept.ac.in 
TVD envisages active involvement of client and early involvement of the contractor in the design process along with collaboration between client, contractor, and client, which is far different from typical design and construction processes. In general, silo-based design is practiced and the contractor comes on the canvas of construction project only after the award of work (Landgren et al. 2018). The utilization of TVD in the construction industry hinges on imparting hands-on knowledge to the young construction professionals about value addition of this innovative lean tool.

In this context, this paper discusses the development and testing of a TVD simulation exercise at a prominent university in India. This paper comprises five sections; beginning with the introduction described here, the paper processed to provide an overview of TVD and its application in the construction industry in the second section. The third section describes the development of the simulation, followed by its testing in the fourth section. The paper concludes with a post-simulation discussion as the fifth and final section of the paper.

\section{TARGET VALUE DESIGN}

The primary driver for the simulation is the hypothesis described by Ballard, G., 2008 stating that facilities better fit for purpose can be provided at less cost through rigorous project definition and through lean design and construction; i.e. through the lean project delivery system. The lean project delivery system involves helping the clients decide what they want, rather than simply developing what they ask.

The expected cost, as defined by Ballard, G., 2008 is the forecast or estimated cost of the project at current best practice. This Expected Cost is referred to as the "Market Cost" in the simulation described in this paper. The Target Cost, referred to as is in the simulation, is what the team commits to deliver, and is typically set below the expected cost in order to spur innovation beyond current best practice. Once a target cost has been established, the project is collaboratively designed to that target cost (Ballard \& Rybkowski, 2009).

TVD is an adaption of target costing. Ballard, G., 2009 describes TVD as a management practice that drives design to deliver customer values within project constraints. TVD is driven by an awareness of costs and constructability by harnessing a collaborative approach towards design development. TVD offers designers an opportunity to engage in the design conversation concurrently with those people who will procure services and execute the design (Macomber, Howell, \& Barberio, 2008).

From a practical viewpoint of TVD implementation in the industry, researchers have reported that TVD projects have been completed at $15 \%$ to $20 \%$ below the market price without compromising schedule or quality (Ballard \& Rybkowski, 2009). Do et al., 2014 further reinforces these findings through their extensive study of 47 TVD projects, wherein TVD has been noted to be advantageous in controlling the project's budget, by making cost a design constraint from early on. Further, better coordination has been reported by the early involvement of trade partners during the design.

AIA, 2017 describes Integrated Project Delivery (IPD) as a project delivery approach that collaboratively harnesses the talents and insights of all participants to optimize project results, increase value to the owner, reduce waste, and maximize efficiency through all 
phases of design, fabrication, and construction. It further states Building Information Modeling (BIM) as one of the most powerful tools supporting IPD by combining all aspects of a project into one common database for collaboration throughout the project development.

Ballard, G., 2008 describes defining target cost, promoting collaboration and rapid estimating as some of the major steps involved in Design Development in Lean Project Delivery. The simulation highlighted in the paper is based on Target Value Design through Integrated Project Delivery, supported by rapid cost feedback using BIM.

\section{SIMULATION DEVELOPMENT}

The demand for construction managers has been increasing continuously because of rapid infrastructure development being experienced in India. As a result, many universities have been offering masters level courses (Master of Technology - M.Tech.) in the domain of Construction Engineering and Management. There has been increasing concern amongst the construction industry fraternity over industry readiness of construction management graduates coming out of these various masters level programmes.

There has been an increasing focus to simulate practical construction site environment in a classroom setting and increased interaction with industry professionals to address these concerns. Along these lines, the authors of this paper who were teaching a studio course named "Construction Project Formulation and Appraisal" as part of the M.Tech Construction Engineering and Management programme at an Indian University developed and tested a simulation of TVD method. The studio course aims to bring real-life problems into the classroom and equips students to solve these problems with the application of theoretical concepts. In reality, it attempts to bridge the gap between theory and practice. The aim of this studio is to equip students with the necessary knowledge and skills for performing appraisal of construction project from the viewpoint of finance, economics, design, and engineering.

There were 24 students taking part in this studio, of which 6 students had a prior educational degree (Bachelor's) in Architecture (known as B. Arch), while the rest had an undergraduate degree in Civil Engineering (known as B.E/B.Tech - Civil). Many of these students had work experience ranging from 2 to 3 years. Of these 24 students, six groups were created and each of these groups had a student with B. Arch qualification and with work experience. The groups were designed to foster cross-learning among students of different educational backgrounds, to hasten the learning trajectories of students without work experience, and to transition students with work experience into the learning mode by raising questions/queries on set practices in the construction industry.

The instructors provided a list of potential projects to be appraised in this studio. This list contained projects from varied sectors like industrial, infrastructure, and real estate. These projects were either in the proposal stage, indicated as in pipeline stages by government departments or private developers, or were at the preliminary stages of construction. The projects were allocated to the groups based on their interests. The groups were expected to perform appraisal of assigned project by collection and analysis of primary as well as secondary data. The primary data was collected from interviews with 
stakeholders like project proponents, public sector organizations involved in the approval and implementation of the project, industry groups, think tanks and non-governmental organizations. The secondary data was in the form of traffic survey, minutes of meeting, census and demographic parameters, governmental policies, and contracts. The following appraisals were typically carried out by each group: demand and market assessment, technical analysis, legal compliances, project conceptualization and planning, financial analysis, technical analysis, project structuring, and procurement strategy, stakeholder analysis, environmental impact assessment, risk analysis, and project controls. Based on the availability of primary and secondary data, each group performed in-depth analysis or assessment of a few topics, although, the instructors ensured breadth in terms of areas to be typically analysed. Following is the list of projects selected: 1) Garment Factory, Ranoda, 2) ITC Narmada Hotel, 3) Redevelopment of Gandhinagar Railway Station, 4) Vadodara Mumbai Expressway, 5) Surat Metro Rail and 6) Aquatics Gallery, Science City.

To begin with, the student groups investigated the project characteristics covering factors like location, transport connectivity and stakeholders associated with the project. These factors helped in carrying out locational analysis that focused on the advantages and disadvantages associated with the actual project site as well as other potential sites. After completion of this analysis, the studio discussion focused on technical analysis. It comprised the development of design brief, proposed design, and target value design. The students collected information pertaining to bylaws, standards and specifications, site characteristics and guidelines relevant for design development. They also analysed the design features of existing projects having similar scale and area.

The members of each students group were divided into three roles: client, contractor, and designer. Typically, there were 4 students in each student group. The role of designer was assigned to 1 student having bachelor's degree in architecture, while students having work experience and no experience played the roles of the contractor (1 No.s) and client (2 No.s), respectively. The rationale behind the assignment of these roles was to harness the educational background and experience of a student to play the role effectively. The simulation was conducted in two steps; the first step involved emulating silo-based design, wherein the designer, contractor, and client worked independently, within their functional silos. The instructor has used the formats as mentioned in Designing Buildings Wiki (Strategic Brief for construction projects, 2018) for preparation of project brief and design brief. The project brief defines the Client's requirements for the development of the built asset. It is the key document upon which the design will be based. The project brief includes project information, spatial requirements, technical requirements, component requirements, and other issues. Each student group was instructed to select a specific portion of their construction project for the purpose of detailed design. The students were told to design either of the following: structural system, MEP system, and lighting system. Apart from these detailed design features, each group has covered basic design features related to material, layout or space, methods or systems, and specifications. Considering the time available for this simulation and prior skills with the students, it was impractical to perform the detailed design of not only the entire project but also a specific portion of their projects. 


\section{DEVELOPMENT OF DESIGN OPTION -D1}

Each student was told to select a specific component of their project for the TVD simulation. Firstly, the student playing the role of Client was instructed to develop a project brief for the selected component. The developed project brief was communicated to the designer via email. Since the beginning of this TVD simulation, the students were asked to mark a copy of the email communication to the instructor, with an aim to understand the information flow among the team members. The developed project brief was communicated to the designer. With reference to this project brief, the designer has developed a design brief, following the components described in Designing Buildings Wiki (Project Brief for design and construction, 2019). The student playing the role of Designer has finalised the design brief in consultation with the Client members. Afterward, the designer has developed the Design in 2D format. While developing the Design option - D1, the designer was instructed to note the number of requests for information (RFI) sought, along with the total duration taken to complete the design. After the finalisation of D1, this design was communicated to the contractor team member for estimating the cost of selected project component. This cost was named as market cost (C1).

\section{DEVELOPMENT OF DESIGN OPTION - 2 (D2)}

This stage of the design has broken the silos which exist between the Client, Contractor, and Designer, involving collaborative working between these team members. Firstly, the students were exposed to the concept of Target Value Design with the circulation of relevant reading material. It was followed by classroom discussion on challenges associated with silo-based designing and its implications on time and cost performance of projects. Subsequently, the benefits that can be derived from TVD were discussed and debated in the class. In this second round, each group of students was instructed to declare Target Cost for their selected project component. The classroom discussion focused on various ways of designing to Target Cost. It involved case discussion on how material, layout, space, methods, system, and specification can be changed for achieving the Target Cost. The instructors have decided to use the power of Building Information Modeling (BIM) for providing cost feedback during the design process. The benefits of cost feedback in the design process, with the help of BIM, has been discussed by Nguyen et al., 2018. The instructors were inspired by this paper and decided to involve BIM modelers in the preparation of D2. The BIM modeler was a new addition to the existing team, expected to play a passive role in the simulation exercise. This role involved the transformation of design D1 into firstly, BIM models, followed by the development of BIM model with relevant cost. The BIM modeler was present during the process of development of D2 by showing visualisation of design changes suggested by the team and its effect on cost. This iterative process helped in arriving at D2. The attention of students was specifically drawn towards the detailed design for a particular system while preparing D1. Therefore, the students can make detailed changes in the selected design system. Afterward, the groups were instructed to commence the Design Option - D2. The students were instructed to keep the project brief and the design brief, prepared as part of Round - 1, unchanged. It ensured no change in the design goalpost is entertained while preparing D2. The students were expected to work in a collaborative manner for preparation of D2 and were asked to note 
the time of completion for this design option. The developed design D2 was reviewed and confirmed by the owner. Each group of students was asked to communicate the time taken for the development of D2 and confirmation of D2 with the owner. The team has calculated the cost of D2, which is called the Actual Cost of Design. Finally, the groups were asked to understand the difference between the market cost, target cost and the actual cost for their projects.

\section{SIMULATION TESTING}

The simulation was tested for the $\mathrm{M}$. Tech programme students of a prominent university in India. The composition of the student groups is discussed in Simulation Development section. The project components selected by these groups, along with the system for detailed design is shown in Table 1.

Table 1: Project component and detailed design component developed by the groups

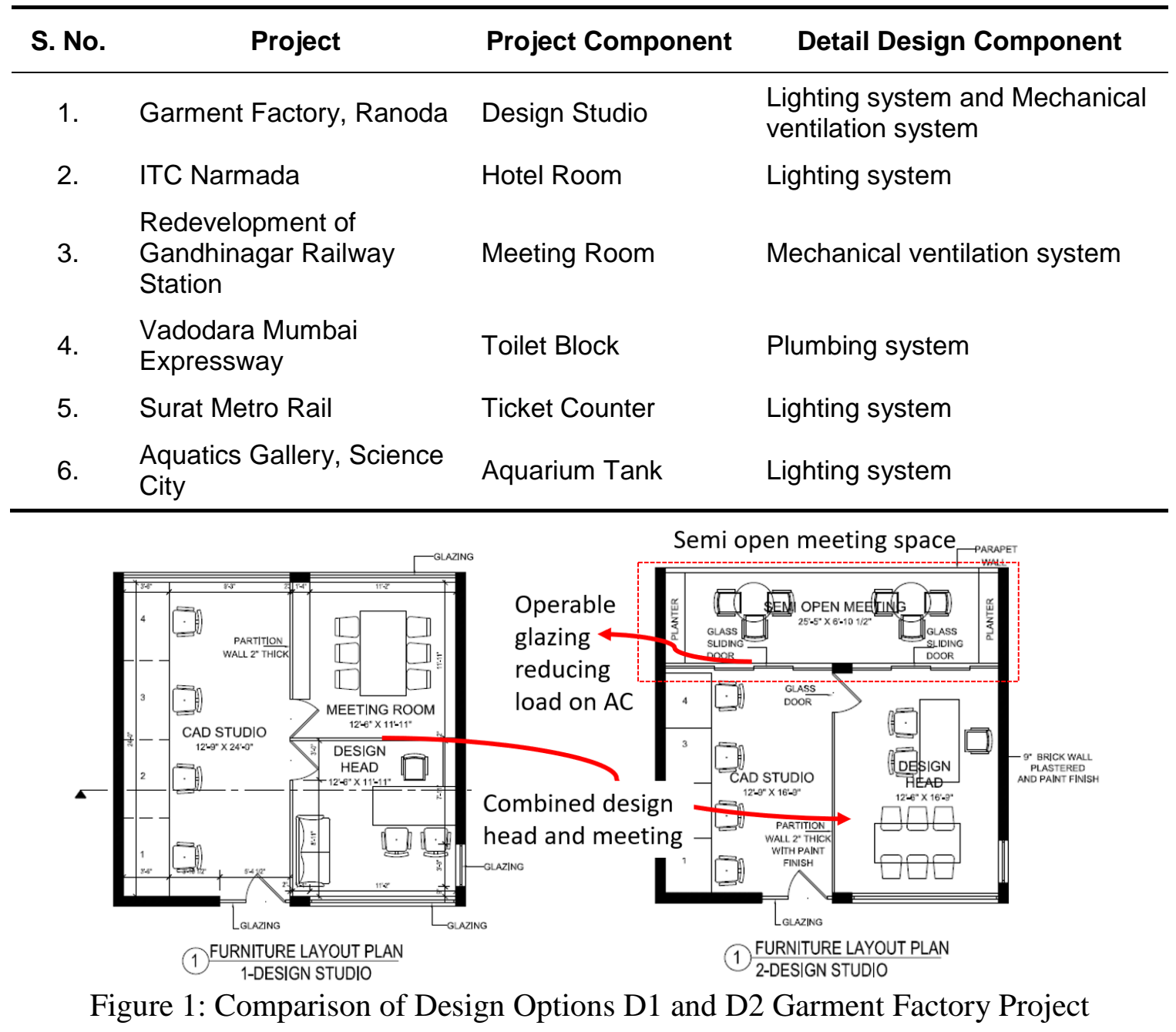


In Round - 1, the students developed design D1 and arrived at related cost $\mathrm{C} 1$. This was followed by Round -2 , involving declaration of Target Cost, and making required changes in the design for arriving at design D2. Table 2 shows the type of changes made by each team, and the associated costs - Market Cost, Target Cost and Actual Cost (Refer Figure 1 and Figure 2).

Table 2: Types of change and the associated costs for the project component

\begin{tabular}{|c|c|c|c|c|c|}
\hline $\begin{array}{l}\text { S. } \\
\text { No. }\end{array}$ & Project & $\begin{array}{l}\text { Type of } \\
\text { Change }\end{array}$ & $\begin{array}{l}\text { Market Cost } \\
\text { in USD (C1) }\end{array}$ & $\begin{array}{l}\text { Target Cost } \\
\text { in USD }\end{array}$ & $\begin{array}{l}\text { Actual Cost } \\
\text { in USD (C2) }\end{array}$ \\
\hline 1. & $\begin{array}{l}\text { Garment Factory, } \\
\text { Ranoda }\end{array}$ & $\begin{array}{l}\text { Material Type } \\
\text { Layout or space } \\
\text { Specifications }\end{array}$ & $16,353.09$ & $13,082.94$ & $13,499.59$ \\
\hline 2. & ITC Narmada & $\begin{array}{l}\text { Material Type } \\
\text { Layout or space }\end{array}$ & $75,635.55$ & $64,292.27$ & $60,854.81$ \\
\hline 3. & $\begin{array}{l}\text { Redevelopment of } \\
\text { Gandhinagar } \\
\text { Railway Station }\end{array}$ & $\begin{array}{l}\text { Material Type } \\
\text { Methods or } \\
\text { Systems }\end{array}$ & $49,371.29$ & $41,965.59$ & $39,114.97$ \\
\hline 4. & $\begin{array}{l}\text { Vadodara Mumbai } \\
\text { Expressway }\end{array}$ & $\begin{array}{l}\text { Material Type } \\
\text { Layout or space }\end{array}$ & $11,123.53$ & $10,011.17$ & $9,086.18$ \\
\hline 5. & Surat Metro Rail & $\begin{array}{l}\text { Material Type } \\
\text { Layout or space } \\
\text { Specifications }\end{array}$ & $5,915.66$ & $5,324.10$ & $5,206.81$ \\
\hline 6. & $\begin{array}{l}\text { Aquatics Gallery, } \\
\text { Science City }\end{array}$ & $\begin{array}{l}\text { Material Type } \\
\text { Specifications }\end{array}$ & $4,852.63$ & $4,367.52$ & $4,174.47$ \\
\hline
\end{tabular}

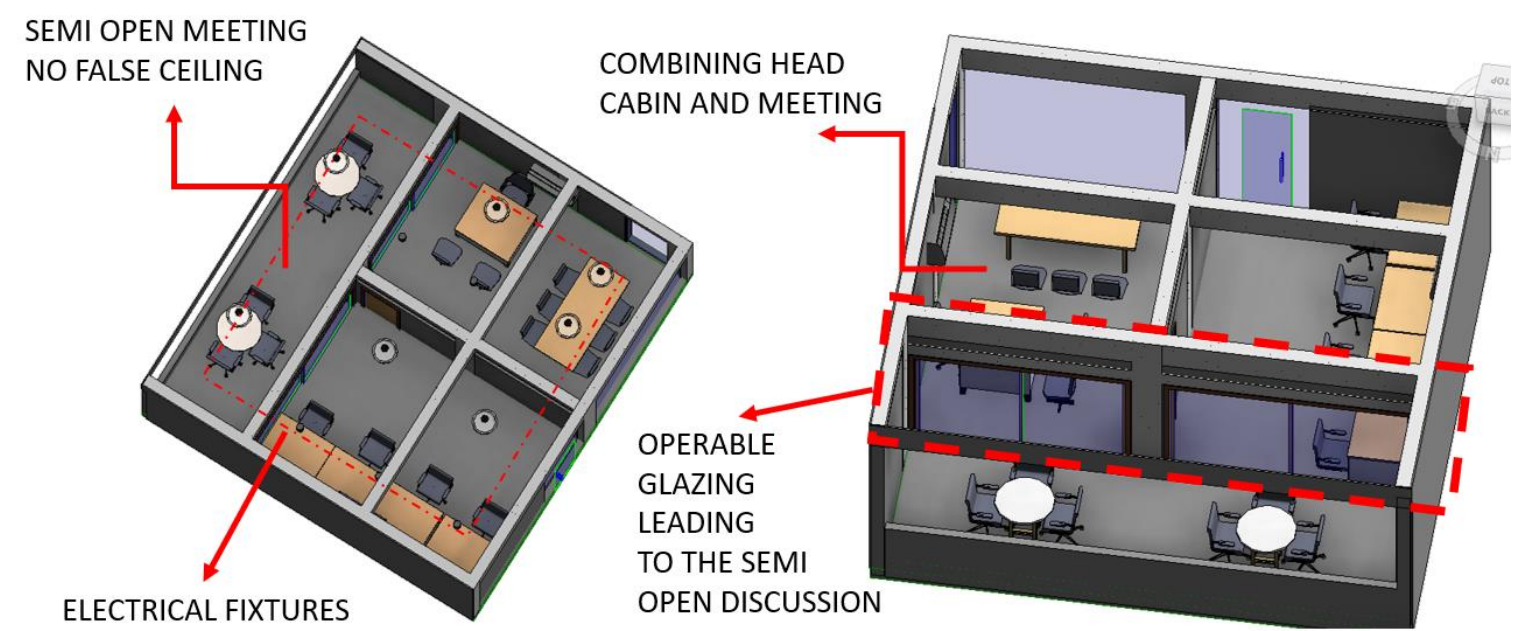

Figure 2: Revit model showing Design Option - D2 for Garment Factory Project 


\section{POST SIMULATION DISCUSSION}

The instructor decided to understand the effectiveness of this TVD simulation exercise. During the literature review, the authors came across a simulation developed by Rybkowski et al., 2016, called Tower game for TVD. The thesis document (Munankami, 2012) discusses in detail rationale for the development of Tower Game, simulation development and provides an evaluation questionnaire for evaluating the effectiveness of Tower Game. This questionnaire was used for assessing the effectiveness of the TVD simulation undertaken by the authors. The reason being this questionnaire captures the majority of the elements that have been simulated as part of this exercise. Along with these questions, few questions were designed by the authors for understanding the benefits derived from the involvement of the BIM modeler in this exercise. After completion of simulation exercise, a Google Form was created and circulated among the students for inputs. The students were asked to rate various parameters on a 5-point Likert scale; 5 (most effective) to 1 (least effective). The analysis of the responses is as follows.

\section{PARTICIPANT'S RESPONSE TO QUESTIONS ABOUT IPD}

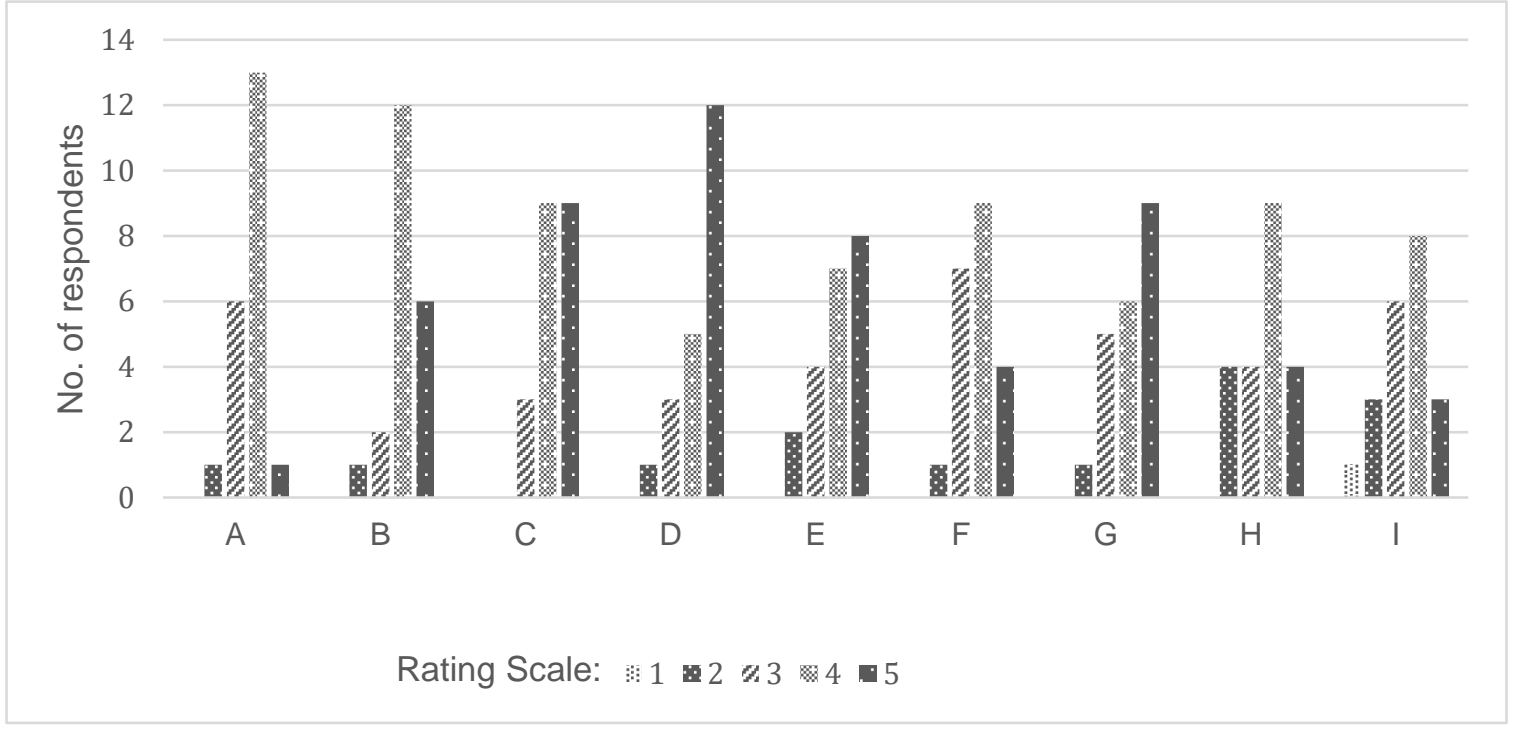

Figure 3: Histogram showing participant's response to questions about IPD

A - Mutual respect and trust, B - Mutual benefit and reward,

$\mathrm{C}$ - Collaborative innovation and decision making,

D - Early involvement of key partners, E - Early goal definition

$\mathrm{F}$ - Intensified planning, $\mathrm{G}$ - Open communication

$\mathrm{H}$ - Appropriate technology, I - Organisation and leadership

Based on the analysis of responses shown in Figure 3, it has been observed that majority of participants understood the value brought by the early involvement of key partners in the design process of a project. Further, the participants understood collaborative 
innovation and decision making and open communication improves the outcome of the design and construction process. Overall, most of the participants agreed that the simulation exercise helped in appreciating softer or cultural aspects of the IPD process, such as mutual respect and trust, mutual benefits and reward. Surprisingly, the appropriate technology was not highlighted as key learning from this TVD simulation.

\section{PARTICIPANT'S RESPONSE TO QUESTIONS ABOUT TVD}

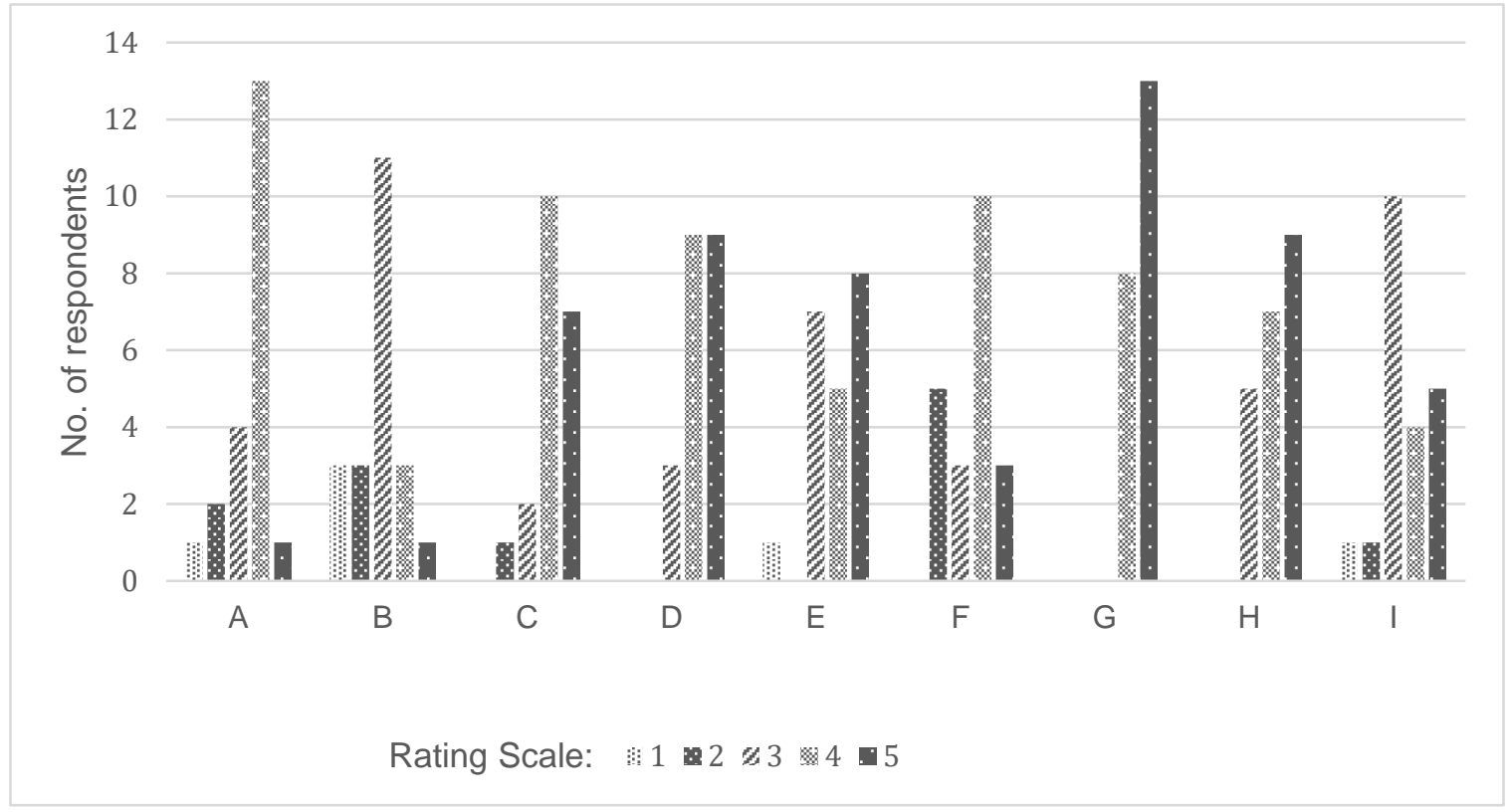

Figure 4: Histogram showing participant's response to questions about TVD

A - Project business care and decisions, B - Feasibility study

$\mathrm{C}-$ Client is an active member of the team

D - Understanding the values of customer, E - Relational contract between parties

F - Costs \& schedule targets cannot be exceeded and only customer can change scope

$\mathrm{G}-$ Continuous estimating \& budgeting through collaboration among team members

$\mathrm{H}$ - Frequent update of estimates among teams, I - Co-location

Based on the analysis of responses shown in Figure 4, it can be observed that this exercise has immensely helped the participants to understand continuous cost feedback during the estimating and budgeting process, helps in collaboration amongst the team members, and it helps in not only the achievement of target costs, but also satisfying the values of customer. The authors have decided to involve BIM modeler as an intervention to improve the TVD exercise with the premise that continuous cost feedback can hasten the design revisions and achievement of customer values. The findings from the questionnaire corroborate the hypothesis made by the authors prior to the study. Most of the participants 
agreed that the active involvement of Client plays an important role in the achievement of target cost.

\section{PARTICIPANT'S RESPONSE TO QUESTIONS ABOUT BIM}

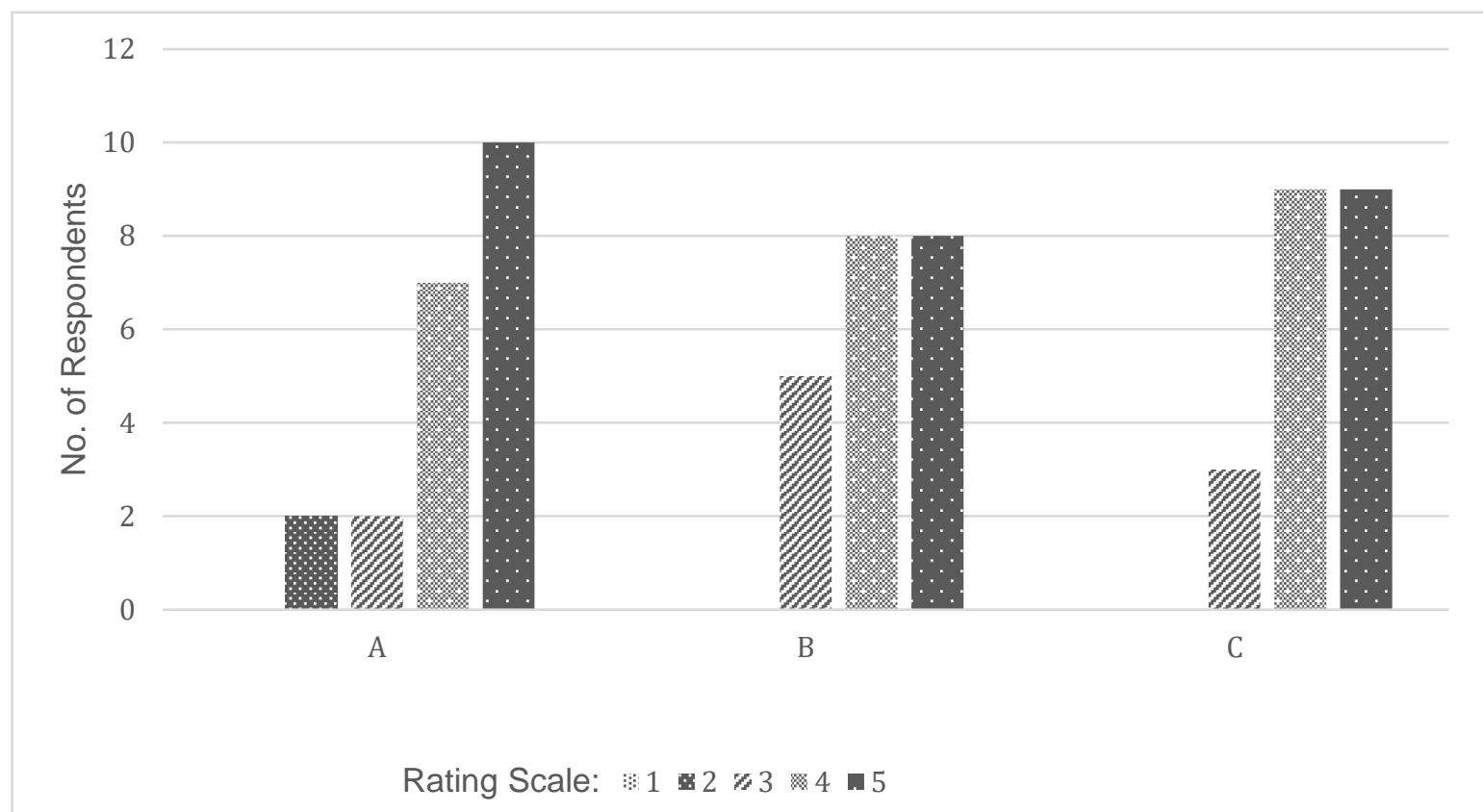

Figure 5: Histogram showing participant's response to questions about BIM

A - BIM in developing D2, B - Role of BIM modeler in the design process

$\mathrm{C}-\mathrm{BIM}$ in providing rapid cost feedback while developing multiple design alternatives

The analysis of responses, shown in Figure 5, highlights that the involvement of BIM modeler helped in the preparation of alternate designs and provided rapid cost feedback to the team. Therefore, it indicates the value addition of BIM modeler in the design preparation of D2. As indicated by (Nguyen, Tommelein, \& Martin, 2018), value addition of BIM in generating rapid cost feedback in the estimating and costing process, the similar scenario has been observed in this TVD simulation.

\section{CONCLUSION}

The study has indicated that the simulation exercise developed by the authors was useful to the students in imparting hands-on knowledge on working in the environment envisaged in TVD, as well as benefits by this innovative Lean tool. The contribution of this TVD exercise lies in involving BIM modeler in the design process, which not only tries to depict the revamped cost feedback process, as discussed by (Nguyen et al. 2018) but also simulates TVD experience of the real-life project in the classroom environment. This simulation exercise can be further developed and improved by including more number of construction systems in the detailed design, as well as standardising some of the design components. 


\section{REFERENCES}

American Institute of Architects, AIA. (2007). Integrated Project Delivery: A guide. Washington, DC: AIA.

Ballard, G. (2008). The lean project delivery system: An update. Lean Construction Journal, 1-19.

Ballard, G. (2009). an update on Target Value Design. St. Louis: Lean Design Forum Lean Construction Institute \& Project Production System Laboratory.

Ballard, G., \& Rybkowski, Z. K. (2009). Overcoming the hurdle of first cost: Action research in target costing. The 2009 Construction Research Congress (p. 10). Seattle, WA: Construction Institute of ASCE.

Denerolle, S. (2013). Technical Report: The application of Target Value Design to the design phase of 3 hospital projects. Berkeley, CA: P2SL:Project Production Systems Laboratory.

Do, D., Chen, C., Ballard, G., \& Tommelein, I. D. (2014). Target Value Design as a method for controlling project cost overruns. IGLC, (pp. 171-181). Oslo, Norway.

Landgren, M., Jakobsen, S. S., Wohlenberg, B., \& Jensen, L. M. (2018). Integrated design processes - a mapping of guidelines with Danish conventional 'silo' design practice as the reference point. Architectural Engineering and Design Management.

Macomber, H., Howell, G., \& Barberio, J. (2008). Target-Value Design: Nine Foundational and Six Advanced Practices For Delivering Surprising Client Value. Lean Project Consulting.

Munankami, M. B. (2012). Development and testing of simulation (game) to illustrate basic principles of Integrated Project Delivery and Target Value Design: A first run study. College Station.

Nguyen, H. V., Tommelein, I. D., \& Martin, P. (2018). Process-based cost modeling framework and case study. IGLC, (pp. 46-57). Chennai.

Project Brief for design and construction. (2019, Jan 03). Retrieved from Designing BuildingsWiki:https://www.designingbuildings.co.uk/wiki/Project_brief_for_design_ and_construction

Rybkowski, Z. K., Munankami, M. B., Shepley, M. M., \& Fernández-Solis, J. L. (2016). Development and testing of a Lean simulation to illustrate key principles of Target Value Design: A first run study. IGLC, (pp. 133-142). Boston.

Strategic Brief for construction projects. (2018, Feb 27). Retrieved from Designing BuildingsWiki:https://www.designingbuildings.co.uk/wiki/Strategic_brief_for_constr uction_projects 
Devkar, G., Trivedi, J., and Pandit, D.

Proceedings IGLC - 27, July 2019, Dublin, Ireland 